\title{
The Lived Experiences of Iranian Women, Injured from Their Husbands' Infidelity
}

\author{
Maryam Fatehizade ${ }^{1}$, Akram Rahimi $^{2} \&$ Zahra Yousefi $^{3}$ \\ ${ }^{1}$ Department of Counseling, Faculty of Education and Psychology, University of Isfahan, Iran \\ ${ }^{2}$ Department of Psychology, Islamic Azad University, Isfahan (Khorasgan) Branch, Iran \\ ${ }^{3}$ Department of Educational and Psychology, Islamic Azad University, Isfahan (Khorasgan) Branch, Iran \\ Correspondence: Maryam Fatehizade, Department of Counseling, Faculty of Education and Psychology, \\ University of Isfahan, Iran. Tel: 9831-3793-2515. E-mail: m.fatehizade@edu.ui.ac.ir
}

Received: December 27, 2015

Accepted: January 8, 2015

Online Published: February 2, 2016

doi:10.5539/mas.v10n4p70

URL: http://dx.doi.org/10.5539/mas.v10n4p70

\begin{abstract}
The current study mainly aims to investigate the lived experiences of women who were injured from their husbands' infidelity in city of Isfahan in Iran country. The study was a phenomenological research with a qualitative method. The study population included women of Isfahan, who were injured from their husbands' infidelity. In order to choose samples, the purposive sampling was applied; and a total number of ten women were selected out of all who were injured from their husbands' infidelity. Moreover, the study tools included a semi-structured interview, the questions of which were provided according to the data obtained from the investigation of texts and sources with the purpose of recognizing the lived experiences of women injured from their husbands' infidelity. The process of interviewing the participants continued until the saturation of the category. In order to analyze the data, we applied qualitative analysis and primary and secondary coding and categorizing method. The study results indicated that they lived experiences of women who were injured from their husbands' infidelity, included ten main sub categories which are placed in four levels: confronting with tension, needs, spirituality, cooperation and effective communication.
\end{abstract}

Keywords: lived experiences, injured women, infidelity, Iran

\section{Introduction}

Infidelity is defined as establishing emotional or sexual relationships with someone other than one's wife, while, at the same time, such relationships are hidden. The main feature of infidelity is being mysterious (Brown, 2001). In western countries, marital infidelity is recognized as the third difficult problem in terms of treatment and the second destructive problem with which couples are encountered (Greenberg \& Johnson, 2005). Actually, discovering a hidden relationship would lead to destructive effects in couples. Intense emotions in the injured woman fluctuate between her anger towards her betrayer husband and inner feelings of shame, depression, helplessness and exclusion (Gordon et al., 2008). Moreover, possibly feelings of shock, disbelief and denial might replace such emotions (Rosenak \& Harnden, 1992). Marital infidelity would cause intense emotional consequences in couples (Bennet et al., 2002). Injured women often experience feelings such as shame, low self-esteem, depression, helplessness and being trampled (Pittman, 1989). Some of the psychotherapists have reported that the betrayer husband would also be encountered with such feelings as shame, guilt, doubt, anger and frustration (Cano \& Oleary, 2000).

After an infidelity is revealed, intense emotional unrest will be accompanied by cognitive disturbances. Among the important experiences of an injured woman, one can namely mention mental rumination, which can be so uncontrollable and intense that lead to interference, even in one's daily functioning and concentration (Humphry, 1987). Extra marital involvements would take place for both women and men, although individuals' beliefs and behaviors are negative towards extra marital relationships and the consequences. However, the rate of its occurrence differs based on its sampling and its definition; for married individuals who have faced it at least once, it varies from the approximate amount of $12 \%$ to $75 \%$ (Allen \& Baucom, 2004). Infidelity is one of the traumas which can lead to changes in many aspects of one's life. More importantly, not only it affects an individual, but also a family and a community. As a matter of fact, infidelity makes it possible for researchers to 
conduct a qualitative study by applying a phenomenological method, in order to deeply understand and describe the experiences of injured women. Therefore, one can come to such a rich insight and knowledge about these suffering human beings, that helps us to be able to see the world as they do. That is because, it seems necessary to deeply recognize and understand their experiences in order to improve the quality of their lives. As a researcher might believe, the existing truth in the trauma of infidelity must be heard from the injured women, themselves. The recognition of such experiences along with the conditions and concerns of these women is a valuable finding by which one can investigate the issue precisely and comprehensively. In other words, this way infidelity can be seen in the point of view of those who are struggling with it. Therefore, the present study was performed with the purpose of describing and explaining the lived experiences of women who were injured from their husbands' infidelity. Thus, by recognizing and becoming aware of the lived experiences and feelings of injured women and also by applying different aspects of it, this study might be able to be of great help to planners of health care and family consultants to perform appropriate interventions and to design training programs and present counseling in support of these injured women. Furthermore, the present study can encourage psychotherapists to support such injured women, by identifying the factors which affect their experiences.

\section{Method}

The presents study is a qualitative one, in which a phenomenological method was applied according to the fact that the phenomenon under investigation is the lived experiences of women injured from their husbands' infidelity. Indeed, quantitative studies do not have enough flexibility and depth to explore lived experiences of the phenomena which are somehow dealing with human interactions. Therefore, the best method for deeply identifying an experience and the meaning of a complicated phenomenon is phenomenology (Adibi et al., 2012). Phenomenology refers to the understanding of structures or interpretations which people might apply in their routine lives in order to make sense of it; phenomenology also refers to unraveling the meanings which exist in a conversation or a text (Ritchi \& Lewis, 2003).

\subsection{Sample and Population}

The study population included women whose husbands had betrayed them in a period of their marriage. The criteria for the population to enter the study included all women, who were injured from their husbands' infidelity, and also who had the tendency to participate in the study. Moreover, the population was able to provide us with the desired information. The sampling was performed by a purposeful method. Furthermore, the data was gathered through a semi-structured interview, in which the main and central questions of the study were raised. Data collection continued until data saturation was achieved. At the end, the number of participants of the study reached 10 individuals. In an average time of four hours, in a quiet and silent environment, a deep interview was conducted with open questions raised. Therefore, mental information were gathered in order for depicting the real experience of injured women. The major question in this phenomenological study, was to know what is the experience of injured women like, after their husbands' infidelity? And minor questions included: How do these women think about and perceive their husbands' infidelity? And how have these women depicted the image of such betrayal for themselves during the crisis of their husbands' infidelity?

The interviews were all recorded totally on an audio device and were then written word by word. The interviewees were allowed to feel free to describe their experiences during the interviews. Then, we tried to record their real experiences by appropriate interactions, applying successful communication techniques, and perceiving the interviewees' behavior and their non-verbal communications. For data analysis, we applied the coding method and we categorized the interview texts. Finally, this led to the extraction of 106 codes. In the next stage, after reciting the codes repeatedly, the formulated concepts were placed within the thematic categories and clusters and thereof, the main domains (tem?) were obtained. Finally, the obtained domains were placed in general and central concepts, by combining all of the derived beliefs and ideas into a comprehensive description of all details of the phenomenon under investigation. The accuracy of the reliability and validity of the extracted findings was obtained by referring to the participants again, providing comprehensive descriptions and making necessary changes if needed. In addition, the maximum variation of participants was used, in the present study, in order to increase the capability of transferring the findings to other situations or groups. Moral considerations of the study include: obtaining an informed consent from the participants of the study to record their interviews, not mentioning the names of the interviewees, integrity in transferring the interview texts from record to written format, respecting the principle of privacy and confidentiality of the information, and retaining the right to withdraw at any stage of the study. 


\section{Results}

The participants of the present study included 10 women who were injured from their husbands' infidelity. Study participants were in the age range of 23 to 50 years old. Among all participants, four were employed while the other six were housewives. One of the participants had a master degree, three had a bachelor, one had an associate degree, four had a diploma and one had a high school degree. The interviewees were exposed to their husbands' infidelity for different periods of time including: one for 13 years, one for ten years, two for five years, two for four years, three for two years and one for a year. Except one, all other women were still living with their betrayer husband. Data analysis was conducted by coding and categorization method. Among all of the findings, we extracted a total number of 106 conceptual codes and also ten sub main categories, which were placed in four main domains.

\section{Domain 1: confronting with tension}

One of the main domains inferred from the descriptions of women, who were injured from their husbands' infidelity, was confronting with tension. The findings indicated that women who had been exposed to husband infidelity, had experienced tension in various ways. Thus, their answers created some sub categories such as internal stress, physical and psychological status, and fear of divorce. Some of the statements mentioned by the participants in regard of internal stress are as follow: "when one's husband betrays her, nothing more matters even if you have the entire world! I have no idea what happens to my future life! Do I get divorced or just continue to live such miserable life?"

"We have labored for life for many years. We began our life from nothing. Now that my children have grown up, my husband has betrayed me. I feel like empty and worthless. Before my husband's infidelity, I used to play an important role in the family and also I used to support him and my children, but now it's me who needs to be supported by others."

Another sub category derived from the interviews included the physical and psychological status of the interviewees. While stating their experiences, women who were injured from their husbands' infidelity, often mentioned weakness, loosing or gaining weight, boredom, and feelings of self-inferiority and lack of self-confidence as the most important tension that they have confronted with: "since my husband has betrayed me, I have lost my physical strength. I can do nothing anymore. I soon get tired. Most of the days I just lie down on the bed, watching the ceiling; thinking with myself why my husband did so to me. It is now some time that I have been anorexic and have lost weight."

According to the interviews, the imagination of the interviewees was indicative of their mental concern for their future lives and their ultimate fate. One of the factors expressed by these women included their fear of the consequences that might took place due to their husbands' infidelity. Experiencing divorce due to one's husband's infidelity, being revealed among relatives and friends and being afraid of that, all led to the creation of tension in the interviewees: "I'm worried that my husband would betray me again. I knew someone who get divorced after having relationship with a girl. I'm afraid I might have the same future as that of that woman."

Domain 2: the needs

One of the other domains derived from the statements of the interviewees included the needs. The findings of this domain were placed in three sub categories. Among the different aspects which the injured women had experienced due to their husbands' infidelity, one can name need for support, need for awareness and need for education. According to what these people have stated, the support of their main family was one of the most important things which made it easier for them to tolerate what they had been suffering from: "when my family talk about my problem, I feel they are worried about me from the bottom of their heart, specially my mother who plays an important role in supporting me."

Having awareness also plays an important role in reducing the stress and anxiety of the interviewees. Based on the experiences of these women, providing them with accurate and timely information could be effective in reducing their stress: "In case we, women in general, were aware of life skills we could cope with our problems more efficiently. Since we do not know everything about men, we make mistakes in our relationships with them."

On the other hand, the fulfillment of the educational need in injured women had led to an increase in their self-esteem and self-efficacy. In this regard, one of the interviewees stated: "the counselor has taught me to accept the current situation of my life. I gain lots of energy when I go to a psychologist. This way I become more determined to live and continue my life." 


\section{Domain 3: spirituality}

Spirituality was another one of the main concepts which were extracted from the experiences of injured women. Moreover, spirituality included two sub categories of religious beliefs and faith, and hope. Most of the interviewees noted that they are hopeful for the future of their lives by believing in God. Also, they expressed that such belief played an important role in reducing their stress and anxiety. One of the highest manifestations of spirituality in individuals was having hope in God. Such manifestation was reflected by activities such as worship, prayer and pilgrimage to holy places: "I am nothing unless God helps me. I always say Salavat and recite the names of God. This way I can more easily tolerate tortures and difficulties of life. I live only by having trust in God. Whatever takes place is whatever that God wants."

"During this time, I have made lots of vow to God. That's the only thing that makes me calm. I feel like this is God who takes all the problems away of my life."

Domain 4: cooperation and effective communication

The main concept of cooperation and effective communication was derived from the two sub categories of communication with the husband and reaction of the people around. Most of the interviewees considered effective communication with the husband and having trust in him as an encouragement for continuing life and also as a factor for reducing their stress. One of the participants noted that: "I said I trust whatever my husband says and that I will forgive him with all my heart, when he promised he would cut his relationship with that girl. Although this was really hard for me to do so, I tried my best; and that caused me to feel better each day."

Some of the interviewees spoke about the reaction of people around to their husbands' infidelity. Moreover, they were complaining about the viewpoint of people towards such injured women: "It really makes me feel weaker when people around look at me with pity, saying I didn't have the ability to look after my husband. Unfortunately, everyone thinks that I couldn't get my husband sexually satisfied and that's why he has betrayed me."

Table 1. Concepts extracted from analyzing the interviews with study participants

\begin{tabular}{lcc}
\hline Main Domains & Sub Categories & Extracted Codes \\
\hline Confronting with tension & Internal stress & 14 codes \\
& Physical and psychological status & 11 codes \\
& Fear of divorce & 10 codes \\
The Needs & Need for support & 12 codes \\
& Need for awareness & 10 codes \\
Spirituality & Need for education & 10 codes \\
& Religious beliefs & 11 codes \\
Cooperation and effective communication & Faith and hope & 9 codes \\
& Communication with the husband & 11 codes \\
& Reaction of the people around & 8 codes \\
\hline
\end{tabular}

\section{Discussion}

The research aimed to investigate the lived experiences of Iranian women, injured from their husbands' infidelity. The conceptual map which was presented in the study included four main concepts and ten sub categories in search for discovering and describing the experiences of women who were injured from their husbands' infidelity. Most of the problems experienced by the interviewees of the study included tension and stress, which is due to confronting with problems and different aspect of husband infidelity, and need for support and for awareness. The stressful factors in these women included: physical and psychological status of injured women, fear of the consequences of husband infidelity, threatening circumstances and improper situational factors. Accordingly, their family, social and psychological functions were affected by fatigue, anxiety and nervous disorders. Moreover, these injured women had come across with turmoil in different aspects of their lives. The study of Lund Bland and Hansson (2005) confirms the findings of this study, by noting the relationship between marital life and physical and psychological health. Investigating the existing perceptions and experiences indicates that most of the women, who were injured from their husbands' infidelity, have lived a life with low quality. The results of this study are also in consistency with other studies. Spring (1996), believes that an injured woman will encounter a state of arousal and motivation after the disclosure of her husband's infidelity, due to the release of Adrenaline and other tension hormones. Among other consequences of husband infidelity, one can namely 
mention anxiety, chronic restlessness and insomnia. Furthermore, infidelity leads to feel a loss of identity, of being exceptional, of self-esteem, of having control on thoughts and actions, of one's innate sense of order and justice in the world, of communication with others, and of will and determination to live.

Cooperation and communication with the husband and with the people around was also one of the main concepts extracted from the experiences of women who were injured from their husbands' infidelity. Avoidance is the most common behavioral pattern in response to husband infidelity. That is because the injured woman has become highly sensitive, and thereof she would withdrew from her husband following the discovery of the hidden relationship (Rein Stein \& Richards, 1993). Other behavioral responses included being alert, meticulous reprimanding, and other punitive and negative exchanges (Westfall, 1989). An important cognitive response which is stated when an extra-marital relationship is revealed, would be a change in one's beliefs towards her husband and a change in her communication with the husband. Such an individual cannot trust her husband anymore and also cannot feel secure in her relationship with him (Glass \& Wright, 1997). In the present study, one of the helpful aspects for injured women, was their religious beliefs, which helped them to resist against their husband' infidelity and its consequences. Religious activities such as worship and pray and attending religious ceremonies would cause an individual to hope for an endless power. Also, such religious beliefs increase one's tolerance for dealing with the created tension and stress (Adibi et al., 2012).

According to the opinion of the interviewees, being placed in a situation of husband infidelity and encountering new problems has created a feeling of need for awareness in injured women. The degree to which such women are aware of their condition, regarding the way they are going to overcome their husbands' infidelity, is of great importance.

Finally, the lived experiences of women who were injured from their husbands' infidelity is indicative of their urgent need for a careful and sympathetic attention in order for solving their problems and improving the quality of their lives. It seems necessary to understand the feelings and needs of these women. Also, in order to achieve adaption and acceptance, it would be of great help for injured women to do appropriate planning and interventions such as holding family-oriented educational courses, presenting methods of effective communication with people around and also introducing available resources of support. Counselling and training in various areas can play an important role in improving the quality of life for such injured women.

Acknowledgement: we sincerely appreciate it that injured women cooperated with us and accepted to participate in the interview, providing the researcher with their experiences, in spite of their grief and frustration.

Ethical clearance: is adhered all ethical interests: (The ethics of recording data, the right of respondents to end involvement in the research, the disclosure by respondents of sensitive material, the ethics of ethnographic fieldwork, the ethics of the research interview, and ethics in the use of questionnaires).

Conflict of: The authors declare that they have no competing interests.

\section{References}

Adibi, P., Akbari, L., Kahangi, L. S., \& Abdi, F. (2012). Health-state utilities in liver cirrhosis: a cross-sectional study. International journal of preventive medicine, 3(11), 94-101.

Allen, E. S., \& Baucom, D. H. (2004). Adult attachment and patterns of extradyadic involvement. Family Process, 43(4), 467-488. http://dx.doi.org/10.1111/j.1545-5300.2004.00035.x

Cano, A., \& O'Leary, K. D. (2000). Infidelity and separations precipitate major depressive episodes and symptoms of nonspecific depression and anxiety. Journal of consulting and clinical psychology, 68(5), 774.

Glass, S. P., \& Wright, T. L. (1997). Reconstructing marriages after the trauma of infidelity.

Gordon, K. C., Baucom, D. H., \& Snyder, D. K. (2008). Optimal strategies in couple therapy: Treating couples dealing with the trauma of infidelity. Journal of Contemporary Psychotherapy,38(3), 151-160. http://dx.doi.org/10.1007\%2Fs10879-008-9085-1

Greenberg, L. S., \& Johnson, S. M. (2005). Emotionally focused therapy for couples. Guilford Press.

Humphrey, F. G. (1982). Extramarital affairs: clinical approaches in marital therapy. The Psychiatric clinics of North America, 5(3), 581-593.

Lund Bland, A. M., \& Hansson, K., (2005). Relational problems and symptoms in couple therapy. International Journal of social welfare, 14, 256-264.

Pittman, F. S. (1990). Private lies: Infidelity and the betrayal of intimacy. WW Norton \& Company.

Reibstein, J. A., \& Richards, M. (1993). Sexual arrangements: Marriage and the temptation of infidelity. 
Scribner.

Ritchie, J., Lewis, J., Nicholls, C. M., \& Ormston, R. (Eds.). (2003). Qualitative research practice: A guide for social science students and researchers. Sage.

Rosenak, C. M., \& Harnden, G. M. (1992). Forgiveness in the psychotherapeutic process: Clinical applications. Journal of Psychology and Christianity, 11, 188-197.

Shackelford, T. K., Buss, D. M., \& Bennett, K. (2002). Forgiveness or breakup: Sex differences in responses to a partner's infidelity. Cognition \& Emotion, 16(2), 299-307. http://dx.doi.org/10.1080/02699930143000202

Spring, J. A. (1996). After the affair: Healing the pain and rebuilding trust when a partner has been unfaith full. New York: Harper/ Collins.

Westfall, A. (1989). Extramarital sex: the treatment of the Couple. In G. R. Weeks (Ed.), Treating Couples: The intersystem model of the marriage Council of Philadelphia (pp. 163-190). New York: Brunner/ mazel.

\section{Copyrights}

Copyright for this article is retained by the author(s), with first publication rights granted to the journal.

This is an open-access article distributed under the terms and conditions of the Creative Commons Attribution license (http://creativecommons.org/licenses/by/3.0/). 